\title{
Exposure Buildup Factors for Heavy Metal Oxide Glass: A Radiation Shield
}

\author{
Manonara, S. R.; Hanagodimath, S. M.; Gerward, Leif; Mittal, K. C.
}

Published in:

Journal of the Korean Physical Society

Link to article, DOI:

$10.3938 / j k p s .59 .2039$

Publication date:

2011

Document Version

Publisher's PDF, also known as Version of record

Link back to DTU Orbit

Citation (APA):

Manonara, S. R., Hanagodimath, S. M., Gerward, L., \& Mittal, K. C. (2011). Exposure Buildup Factors for Heavy Metal Oxide Glass: A Radiation Shield. Journal of the Korean Physical Society, 59(2), 2039-2042.

https://doi.org/10.3938/jkps.59.2039

\section{General rights}

Copyright and moral rights for the publications made accessible in the public portal are retained by the authors and/or other copyright owners and it is a condition of accessing publications that users recognise and abide by the legal requirements associated with these rights.

- Users may download and print one copy of any publication from the public portal for the purpose of private study or research.

- You may not further distribute the material or use it for any profit-making activity or commercial gain

- You may freely distribute the URL identifying the publication in the public portal 


\title{
Exposure Buildup Factors for Heavy Metal Oxide Glass: A Radiation Shield
}

\author{
S. R. MANOHARA* \\ Department of Physics, Siddaganga Institute of Technology, \\ B. H. Road, Tumkur - 572 103, Karnataka, India \\ S. M. HANAGODIMATH \\ Department of Physics, Gulbarga University, Gulbarga - 585 106, Karnataka, India \\ L. Gerward ${ }^{\dagger}$ \\ Department of Physics, Technical University of Denmark, DK-2800 Lyngby, Denmark \\ K. C. Mittal \\ Electron Beam Center, APPD, Bhabha Atomic Research Center, Mumbai-400 085, India
}

(Received 26 April 2010)

\begin{abstract}
Gamma ray exposure buildup factors for three Heavy Metal Oxide (HMO) glass systems, viz. $\mathrm{PbO}-\mathrm{Bi}_{2} \mathrm{O}_{3}-\mathrm{B}_{2} \mathrm{O}_{3}, \mathrm{PbO}-\mathrm{B}_{2} \mathrm{O}_{3}$, and $\mathrm{Bi}_{2} \mathrm{O}_{3}-\mathrm{B}_{2} \mathrm{O}_{3}$ glasses are presented. The computations were done by interpolation method using the Geometric Progression fitting formula and ANSI/ANS6.4.3 library for the energy range from 0.015 to $15 \mathrm{MeV}$, up to penetration depths of $40 \mathrm{mfp}$ (mean free path). The buildup factors have been studied as functions of incident photon energy and penetration depth. The variations in the buildup factor, for all the glass systems, in different energy regions, have been presented in the form of graphs. Buildup factors of these HMO glasses cannot be found in any standard database, but they are useful for practical calculations in gamma ray shield designs, and they also help to determine and control the thickness of the shielding material used.

PACS numbers: 28.41.Qb, 87.53.Qc

Keywords: Gamma radiation, Interaction of radiation with matter, Buildup factor, G-P fitting formula, Glasses, Radiation shielding, Multiple scattering DOI: $10.3938 /$ jkps.59.2039
\end{abstract}

\section{INTRODUCTION}

As technology advances, there is a constant need to develop materials, which can be used under a hostile environment of high nuclear radiation exposure and can act as a good radiation shield [1]. In this regard, glasses are promising materials because of their homogeneity and range of composition. Typical applications of radiation shielding glasses are in hospital X-ray rooms, radiation therapy rooms, airport security X-ray screens, for materials testing, nuclear facilities, dental clinics, laboratories, X-ray and radiation protection spectacles. Glasses are also used in space technology for protecting human beings and equipment from harmful radiation such as gamma and cosmic rays. Glass has also been suggested for the containment of radioactive waste products.

In general, the Heavy Metal Oxide (HMO) glasses, based on for example $\mathrm{PbO}$ or $\mathrm{Bi}_{2} \mathrm{O}_{3}$ [2-6], have potential applications in radiation shielding, since they have large

\footnotetext{
*E-mail: sr.manohara@yahoo.com
}

${ }^{\dagger}$ E-mail: gerward@fysik.dtu.dk absorption cross section for radiation and at the same time small irradiation effects on their mechanical and optical properties. The HMO glasses are better shields to gamma-radiations and may be used as transparent radiation shielding materials [7]. Recently, bismuth based glasses have received attention due to its many potential applications $[8,9]$. So it becomes a prerequisite to study the interaction of radiation with these glass materials, considering both the primary and the secondary part of the radiation.

The buildup factor helps to determine and control the thickness of the shielding material used. The exposure buildup factor is the photon buildup factor in which the quantity of interest is exposure and the detector response function is that of absorption in air.

In the present work, the gamma ray exposure buildup factors were computed using the Geometric Progression (G-P) fitting formula for $\mathrm{HMO}$ glass systems, viz. $\mathrm{PbO}-$ $\mathrm{Bi}_{2} \mathrm{O}_{3}-\mathrm{B}_{2} \mathrm{O}_{3}, \mathrm{PbO}-\mathrm{B}_{2} \mathrm{O}_{3}$, and $\mathrm{Bi}_{2} \mathrm{O}_{3}-\mathrm{B}_{2} \mathrm{O}_{3}$ glasses in the energy range $0.015-15 \mathrm{MeV}$, and up to penetration depths of $40 \mathrm{mfp}$ (mean free path). The generated exposure buildup factor data has been studied as a function of 


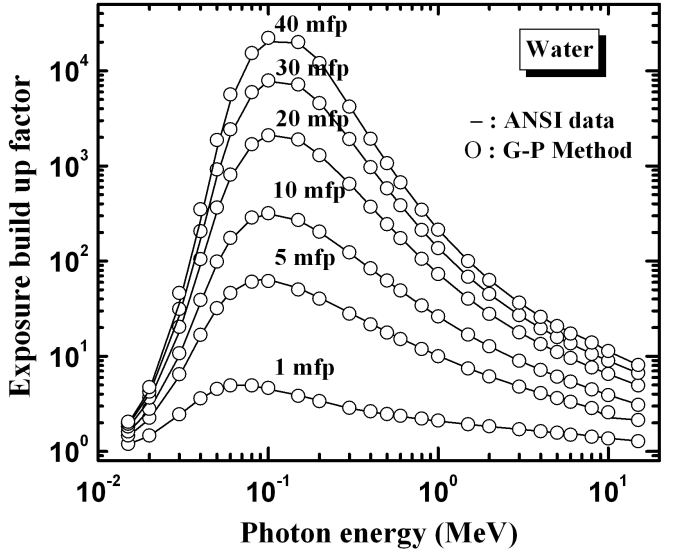

Fig. 1. Exposure buildup factors of water obtained in the present work (circles) compared with those of the ANSI/ANS-6.4.3 standard [15] (solid line) at selected penetration depths (in $\mathrm{mfp}$ ).

incident photon energy and penetration depth. Buildup factors of these HMO glasses cannot be found in any standard database, but they are useful for practical calculations in gamma ray shield designs.

\section{METHOD OF COMPUTATION}

The procedure of calculating the buildup factors has been described in detail elsewhere by the authors [10]. In brief, our computational work can be divided into three steps:

1. Calculation of equivalent atomic number, $Z_{\mathrm{eq}}$. $[11,12]$

2. Calculation of the Geometric-Progression (G-P) fitting parameters using interpolation method. $[11,12]$

3. Calculation of the exposure buildup factors. $[13,14]$

The G-P fitting parameters for exposure buildup factors were computed by the process of interpolation using $Z_{\text {eq }}$ values. Finally, these G-P fitting parameters were used to generate exposure buildup factors for the present glasses using the G-P fitting formula [13,14]. G-P fitting parameters for the pure elements were taken from the standard reference database, ANSI/ANS-6.4.3 [15].

\section{RESULTS AND DISCUSSION}

\section{Standardization of the procedure}

The present method was checked by calculating exposure buildup factors for water in the energy range 0.015 to $15 \mathrm{MeV}$ and up to penetration depths of 40 mfp, and comparing these results with the corresponding ANSI/ANS-6.4.3 data [15]. It can be seen from Fig. 1 that, the present method yields exposure buildup factors for water, which are in excellent agreement with standard data. This gives confidence in our results for the glass materials.
Table 1. Equivalent atomic numbers, $Z_{\mathrm{eq}}$, and exposure G-P fitting parameters for $0.3 \mathrm{PbO}-0.6 \mathrm{Bi}_{2} \mathrm{O}_{3}-0.1 \mathrm{~B}_{2} \mathrm{O}_{3}$ in the energy range $0.015-15 \mathrm{MeV}$.

\begin{tabular}{cllllll}
\hline \hline Energy $[\mathrm{MeV}]$ & $Z_{\text {eq }}$ & $a$ & $b$ & $c$ & $d$ & $X_{\mathrm{k}}$ \\
\hline 0.015 & 65.32 & 0.289 & 1.003 & 0.269 & -0.3022 & 23.00 \\
0.030 & 77.40 & 0.213 & 1.008 & 0.359 & -0.0925 & 16.73 \\
0.040 & 77.94 & 0.248 & 1.016 & 0.318 & -0.0946 & 14.43 \\
0.050 & 78.27 & 0.257 & 1.028 & 0.306 & -0.1033 & 14.07 \\
0.060 & 78.50 & 0.259 & 1.039 & 0.317 & -0.1171 & 14.02 \\
0.080 & 79.01 & 0.177 & 1.486 & 0.753 & -0.1030 & 15.32 \\
0.100 & 77.33 & 0.118 & 1.835 & 0.650 & -0.1279 & 21.79 \\
0.150 & 78.03 & 0.310 & 1.330 & 0.844 & -0.0536 & 16.14 \\
0.200 & 78.37 & 0.391 & 1.181 & 0.306 & -0.1914 & 13.93 \\
0.300 & 78.75 & 0.189 & 1.157 & 0.288 & -0.0934 & 13.54 \\
0.400 & 78.97 & 0.132 & 1.204 & 0.488 & -0.0684 & 14.17 \\
0.500 & 79.10 & 0.105 & 1.254 & 0.601 & -0.0548 & 14.18 \\
0.600 & 79.18 & 0.086 & 1.293 & 0.664 & -0.0439 & 13.75 \\
0.800 & 79.27 & 0.062 & 1.353 & 0.722 & -0.0323 & 13.70 \\
1.000 & 79.32 & 0.048 & 1.389 & 0.789 & -0.0284 & 13.56 \\
1.500 & 79.05 & 0.018 & 1.388 & 0.870 & -0.0206 & 14.53 \\
2.000 & 78.16 & 0.011 & 1.405 & 0.975 & -0.0209 & 13.46 \\
3.000 & 75.95 & 0.015 & 1.400 & 1.012 & -0.0383 & 13.40 \\
4.000 & 74.08 & 0.018 & 1.363 & 1.037 & -0.0437 & 13.72 \\
5.000 & 72.87 & 0.050 & 1.408 & 0.999 & -0.0735 & 13.94 \\
6.000 & 72.09 & 0.058 & 1.427 & 0.954 & -0.0788 & 14.31 \\
8.000 & 71.11 & 0.064 & 1.537 & 0.983 & -0.0852 & 14.14 \\
10.000 & 70.55 & 0.032 & 1.580 & 1.143 & -0.0570 & 14.05 \\
15.000 & 69.92 & 0.012 & 1.750 & 1.344 & -0.0446 & 13.64 \\
\hline \hline
\end{tabular}

\section{Exposure buildup factors of HMO Glasses}

The computed exposure G-P parameters for the present HMO glasses are given in Tables 1 - 3. These parameters have been used to get the buildup factor data. The generated data on exposure buildup factors for the present glass materials have been studied as a function of incident photon energy and penetration depths.

Figures 2(a) - 2(c) show the variation of exposure buildup factors as function of penetration depth for some selected photon energies in the energy range $0.015-$ $15 \mathrm{MeV}$. It can be seen that, the buildup factor is almost constant $[\cong$ unity] for all penetration depths at the lowest energy, i.e., 0.015 MeV. At higher energies, the buildup factor increases with increase in penetration depth for all glass materials. This is because more multiple-scattered photons are generated at large penetration depths thereby increasing the buildup factor.

The exposure buildup factors are shown as function of incident photon energy in Figs. 3(a) - 3(c) for some selected penetration depths from 1 to $40 \mathrm{mfp}$. It can be observed that, buildup factor values are almost constant up to $0.06 \mathrm{MeV}$, and then suddenly have a peak at about $0.1 \mathrm{MeV}$. After this, again there are lower values of buildup factors and then their values are steadily increasing with increasing energy. In case of $0.3 \mathrm{PbO}$ $0.6 \mathrm{Bi}_{2} \mathrm{O}_{3}-0.1 \mathrm{~B}_{2} \mathrm{O}_{3}$ there are two peaks due to the presence of lead and bismuth.

The maximum value of the buildup factor for $0.3 \mathrm{PbO}-$ 
Table 2. Equivalent atomic numbers, $Z_{\text {eq }}$, and exposure G-P fitting parameters for $0.9 \mathrm{PbO}-0.1 \mathrm{~B}_{2} \mathrm{O}_{3}$ in the energy range $0.015-15 \mathrm{MeV}$.

\begin{tabular}{|c|c|c|c|c|c|c|}
\hline Energy $[\mathrm{MeV}]$ & $Z_{\mathrm{eq}}$ & $a$ & $b$ & $c$ & $d$ & $X_{\mathrm{k}}$ \\
\hline 0.015 & 65.29 & 0.289 & 1.003 & 0.269 & -0.3016 & 22.95 \\
\hline 0.030 & 77.23 & 0.212 & 1.008 & 0.361 & -0.0921 & 16.85 \\
\hline 0.040 & 77.70 & 0.248 & 1.017 & 0.319 & -0.0950 & 14.39 \\
\hline 0.050 & 77.99 & 0.258 & 1.028 & 0.306 & -0.1035 & 14.07 \\
\hline 0.060 & 78.17 & 0.259 & 1.040 & 0.317 & -0.1166 & 14.03 \\
\hline 0.080 & 44.55 & 0.782 & 1.711 & 0.028 & -0.2210 & 14.76 \\
\hline 0.100 & 77.11 & 0.120 & 1.831 & 0.664 & -0.1284 & 21.41 \\
\hline 0.150 & 77.80 & 0.312 & 1.326 & 0.805 & -0.0553 & 16.08 \\
\hline 0.200 & 78.09 & 0.388 & 1.179 & 0.302 & -0.1917 & 13.91 \\
\hline 0.300 & 78.42 & 0.188 & 1.158 & 0.301 & -0.0926 & 13.55 \\
\hline 0.400 & 78.61 & 0.131 & 1.206 & 0.496 & -0.0682 & 14.17 \\
\hline 0.500 & 78.72 & 0.105 & 1.257 & 0.606 & -0.0546 & 14.17 \\
\hline 0.600 & 78.79 & 0.086 & 1.296 & 0.668 & -0.0439 & 13.75 \\
\hline 0.800 & 78.88 & 0.062 & 1.357 & 0.727 & -0.0323 & 13.70 \\
\hline 1.000 & 78.92 & 0.048 & 1.393 & 0.794 & -0.0284 & 13.55 \\
\hline 1.500 & 78.67 & 0.017 & 1.390 & 0.878 & -0.0206 & 14.51 \\
\hline 2.000 & 77.89 & 0.010 & 1.406 & 0.977 & -0.0208 & 13.45 \\
\hline 3.000 & 75.91 & 0.015 & 1.401 & 1.012 & -0.0383 & 13.40 \\
\hline 4.000 & 74.25 & 0.018 & 1.362 & 1.036 & -0.0438 & 13.73 \\
\hline 5.000 & 73.17 & 0.050 & 1.404 & 1.002 & -0.0732 & 13.94 \\
\hline 6.000 & 72.47 & 0.058 & 1.421 & 0.956 & -0.0784 & 14.31 \\
\hline 8.000 & 71.58 & 0.064 & 1.525 & 0.985 & -0.0851 & 14.15 \\
\hline 10.000 & 71.10 & 0.032 & 1.562 & 1.144 & -0.0568 & 14.06 \\
\hline 15.000 & 70.55 & 0.012 & 1.724 & 1.343 & -0.0453 & 13.64 \\
\hline
\end{tabular}

$0.6 \mathrm{Bi}_{2} \mathrm{O}_{3}-0.1 \mathrm{~B}_{2} \mathrm{O}_{3}\left[8.91 \times 10^{15}\right] 0.9 \mathrm{PbO}-0.1 \mathrm{~B}_{2} \mathrm{O}_{3}[1.97$ $\left.\times 10^{15}\right]$ and $0.9 \mathrm{Bi}_{2} \mathrm{O}_{3}-0.1 \mathrm{~B}_{2} \mathrm{O}_{3}\left[7.64 \times 10^{8}\right]$ occurs at energies, $E_{\text {peak }}$, equal $0.15 \mathrm{MeV}, 0.15 \mathrm{MeV}$, and 0.1 $\mathrm{MeV}$, respectively, i.e., in the energy range $0.1 \mathrm{MeV}$ - $0.15 \mathrm{MeV}$. $E_{\text {peak }}$ increases slightly with increase in penetration depth, but this is a minor effect. The energy $E_{\text {peak }}$ also increases with increasing $Z_{\text {eq }}$ of the glass materials. At these energies, Compton scattering is the major photon interaction process, and photoelectric absorption is of relatively low importance, leading to large buildup factors. The large value of the buildup factor is attributed due to the fact that, maximum multiple scattering occurs around this energy region $(0.1-0.15 \mathrm{MeV})$ which results in the accumulation of photons, because large numbers of Compton processes are required to degrade the energy of these photons. Therefore, degraded energy photons exist for a longer time, which results in their buildup in the material. Photoelectric absorption has low importance, since these glass materials have high values of effective atomic number, $Z_{\text {eff }}[7,16]$. It is well established that the photoelectric cross-section is proportional to $Z^{4-5}$ and inversely proportional to $E^{7 / 2}$. It follows that, generally, the photoelectric effect is important for the absorption of low-energy photons, in particular for high- $Z$ materials. Hence, the buildup factor is negligible at low energy region $(<0.06 \mathrm{MeV})$.
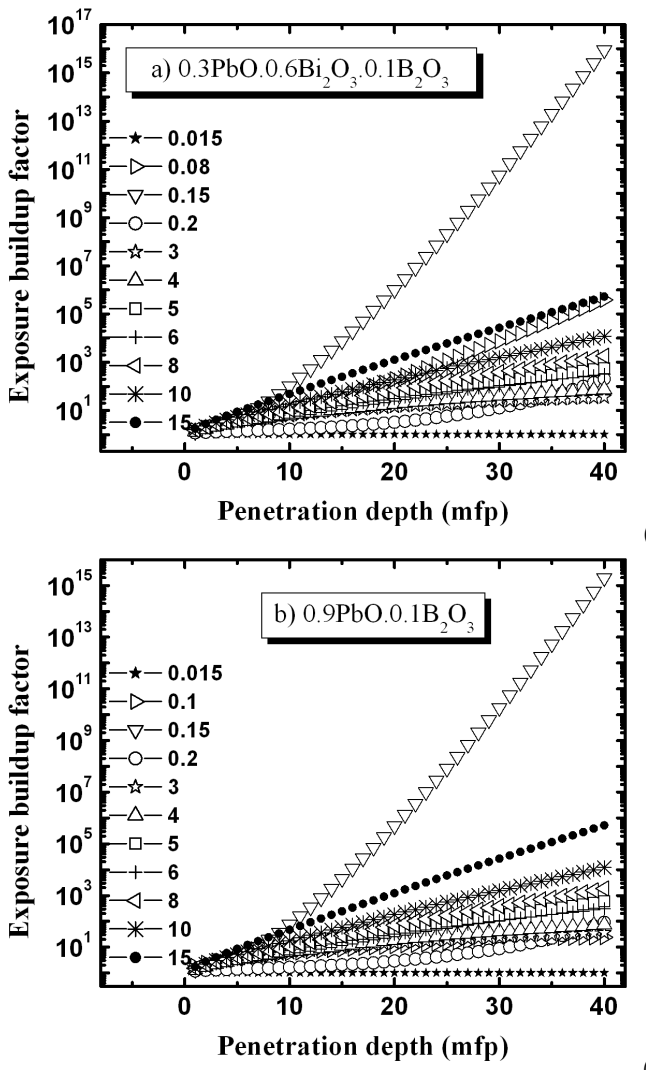

(a)

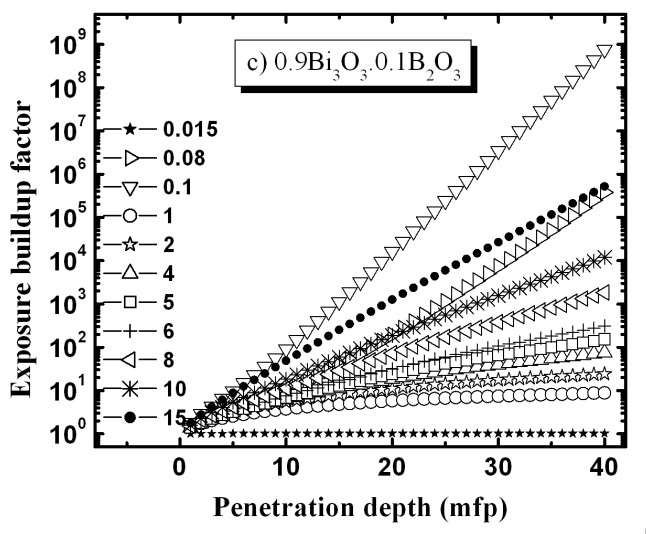

(b)

(c)

Fig. 2. Variation of the exposure buildup factor with penetration depth (in units of $\mathrm{mfp}$ ) for some selected photon energies (in $\mathrm{MeV}$ ): (a) $0.3 \mathrm{PbO}-0.6 \mathrm{Bi}_{2} \mathrm{O}_{3}-0.1 \mathrm{~B}_{2} \mathrm{O}_{3}$, (b) $0.9 \mathrm{PbO}-$ $0.1 \mathrm{~B}_{2} \mathrm{O}_{3}$ and (c) $0.9 \mathrm{Bi}_{2} \mathrm{O}_{3}-0.1 \mathrm{~B}_{2} \mathrm{O}_{3}$.

\section{CONCLUSION}

In the present investigation, the G-P fitting formula has been used for calculating exposure buildup factors of HMO glasses. The buildup factors have been found to vary with photon energy and penetration depth.

The results of the present work on HMO glasses cannot be found in any standard database, but they are useful for practical calculations in gamma ray shield designs, and they also help to determine and control the thickness of the shielding material used. 


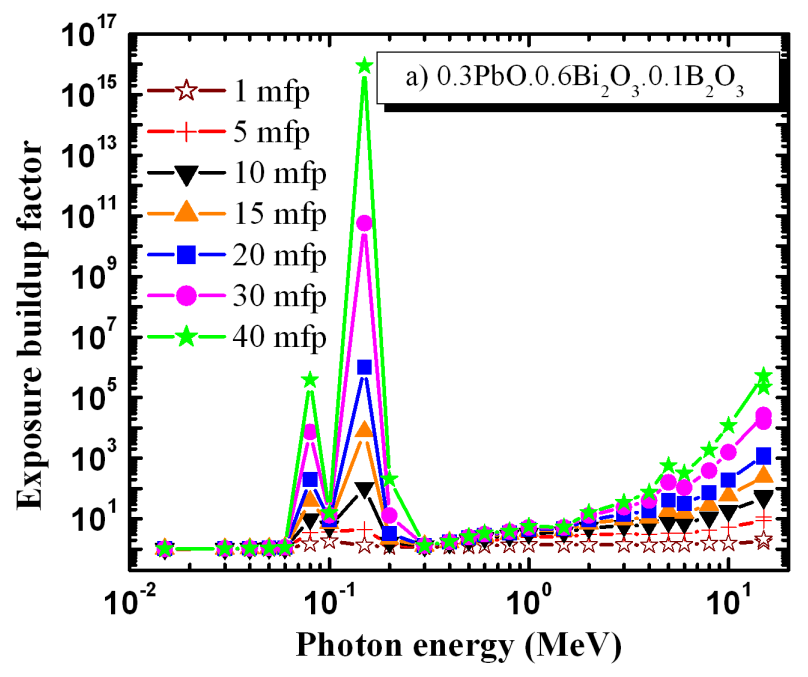

(a)

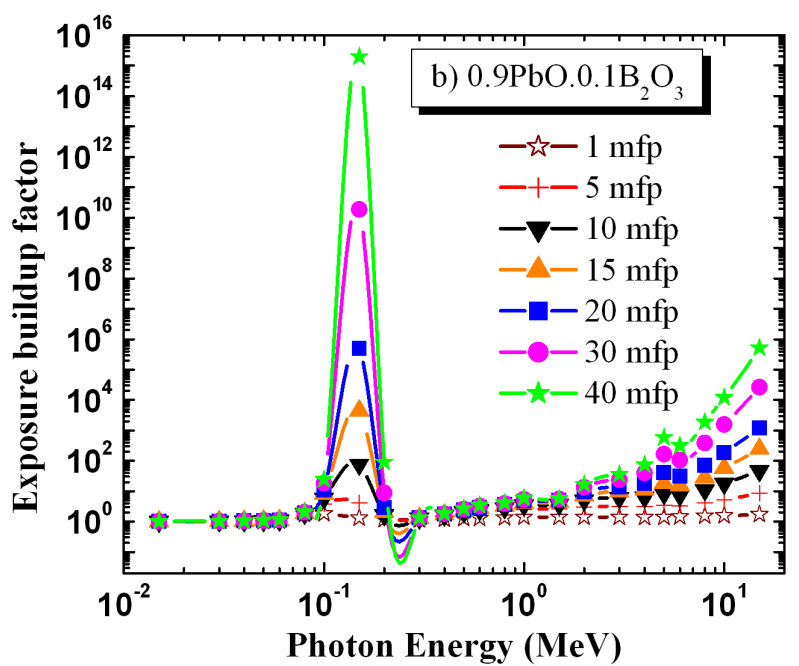

(b)

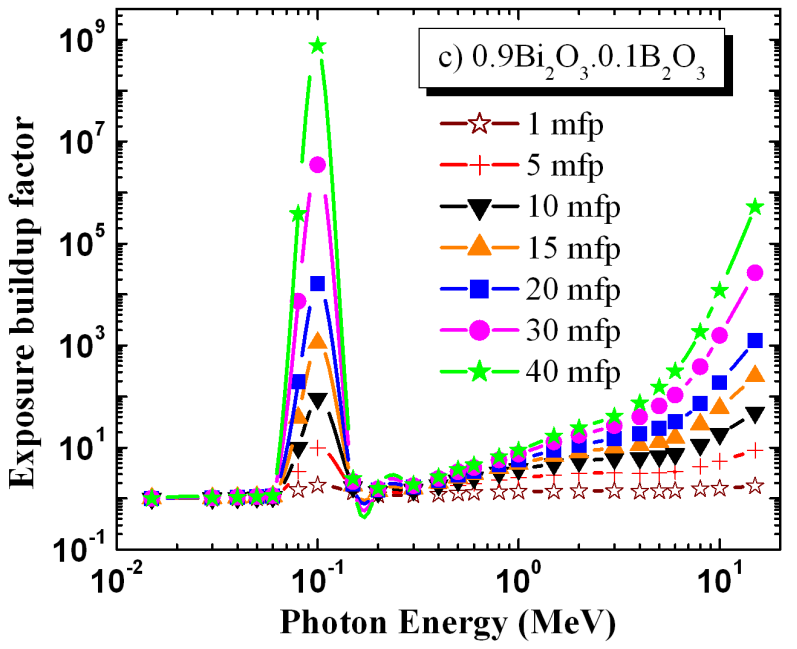

(c)

Fig. 3. (Color online) Variation of the exposure buildup factor with photon energy (in $\mathrm{MeV}$ ) for some selected penetration depths (in units of $\mathrm{mfp}$ ): (a) $0.3 \mathrm{PbO}-0.6 \mathrm{Bi}_{2} \mathrm{O}_{3}-$ $0.1 \mathrm{~B}_{2} \mathrm{O}_{3}$, (b) $0.9 \mathrm{PbO}-0.1 \mathrm{~B}_{2} \mathrm{O}_{3}$ and (c) $0.9 \mathrm{Bi}_{2} \mathrm{O}_{3}-0.1 \mathrm{~B}_{2} \mathrm{O}_{3}$.
Table 3. Equivalent atomic numbers, $Z_{\mathrm{eq}}$, and exposure G-P fitting parameters for $0.9 \mathrm{Bi}_{2} \mathrm{O}_{3}-0.1 \mathrm{~B}_{2} \mathrm{O}_{3}$ in the energy range $0.015-15 \mathrm{MeV}$.

\begin{tabular}{cllllll}
\hline \hline Energy [MeV] & $Z_{\text {eq }}$ & $a$ & $b$ & $c$ & $d$ & $X_{\mathrm{k}}$ \\
\hline 0.015 & 65.33 & 0.293 & 1.003 & 0.269 & -0.3023 & 23.01 \\
0.030 & 77.45 & 0.213 & 1.008 & 0.359 & -0.0926 & 16.48 \\
0.040 & 78.00 & 0.248 & 1.016 & 0.318 & -0.0944 & 13.78 \\
0.050 & 78.33 & 0.257 & 1.027 & 0.306 & -0.1032 & 14.51 \\
0.060 & 78.57 & 0.259 & 1.039 & 0.318 & -0.1172 & 14.18 \\
0.080 & 79.00 & 0.177 & 1.486 & 0.754 & -0.1029 & 15.31 \\
0.100 & 77.38 & 0.117 & 1.836 & 1.142 & -0.1277 & 15.02 \\
0.150 & 78.08 & 0.309 & 1.331 & 0.253 & -0.0532 & 22.72 \\
0.200 & 78.44 & 0.392 & 1.181 & 0.197 & -0.1913 & 15.62 \\
0.300 & 78.83 & 0.190 & 1.156 & 0.447 & -0.0936 & 13.93 \\
0.400 & 79.05 & 0.132 & 1.204 & 0.576 & -0.0685 & 13.72 \\
0.500 & 79.19 & 0.105 & 1.253 & 0.647 & -0.0548 & 14.17 \\
0.600 & 79.27 & 0.086 & 1.292 & 0.697 & -0.0439 & 14.03 \\
0.800 & 79.37 & 0.062 & 1.352 & 0.771 & -0.0322 & 13.76 \\
1.000 & 79.41 & 0.048 & 1.389 & 0.824 & -0.0284 & 13.58 \\
1.500 & 79.14 & 0.018 & 1.387 & 0.954 & -0.0206 & 13.89 \\
2.000 & 78.22 & 0.011 & 1.404 & 0.995 & -0.0209 & 14.08 \\
3.000 & 75.96 & 0.015 & 1.400 & 1.019 & -0.0383 & 13.44 \\
4.000 & 74.04 & 0.018 & 1.363 & 1.037 & -0.0437 & 13.72 \\
5.000 & 72.80 & 0.051 & 1.409 & 0.958 & -0.0736 & 14.13 \\
6.000 & 72.00 & 0.058 & 1.428 & 0.954 & -0.0789 & 14.31 \\
8.000 & 70.99 & 0.064 & 1.540 & 0.983 & -0.0852 & 14.14 \\
10.000 & 70.42 & 0.032 & 1.584 & 1.143 & -0.0570 & 14.05 \\
15.000 & 69.78 & 0.012 & 1.755 & 1.344 & -0.0444 & 13.64 \\
\hline \hline
\end{tabular}

\section{REFERENCES}

[1] J. F. Krocher and R. E. Browman, Effects of radiation on materials and components (Reinhold, New York, 1984).

[2] A. Khanna, S. S. Bhatti, K. J. Singh and K. S. Thind, Nucl. Instrum. Methods Phys. Res. Sect. B 114, 217 (1996).

[3] N. Singh, K. J. Singh, K. Singh and H. Singh, Nucl. Instrum. Methods Phys. Res. Sect. B 225, 305 (2004).

[4] H. Singh, K. Singh, G. Sharma, R. Nathuram and H. S. Sahota, Nucl. Sci. Eng. 142, 342 (2002).

[5] K. Singh, H. Singh, G. Sharma, R. Nathuram, A. Khanna, R. Kumar, S. S. Bhatti and H. S. Sahota, Nucl. Instrum. Methods Phys. Res. Sect. B 194, 1 (2002).

[6] H. Gill, G. Kaur, K. Singh, V. Kumar and J. Singh, Radiat. Phys. Chem. 51, 671 (1998).

[7] S. R. Manohara, S. M. Hanagodimath and L. Gerward, J. Nucl. Mat. 393, 465 (2009).

[8] S. E. Van Kirk and S. W. Martin, J. Am. Ceram. Soc. 75, 1028 (1992).

[9] N. Ford and D. Holland, Glass. Technol. 28, 106 (1987).

[10] S. R. Manohara, S. M. Hanagodimath and L. Gerward, Radiat. Phys. Chem. 79, 575 (2010).

[11] Y. Harima, Nucl. Sci. Eng. 83, 299 (1983).

[12] M. J. Maron, Numerical analysis: A practical approach (Macmillan, New York, 1987)

[13] Y. Harima, Y. Sakamoto, S. Tanaka and M. Kawai, Nucl. Sci. Eng. 94, 24 (1986).

[14] Y. Harima, Radiat. Phys. Chem. 41, 631 (1993).

[15] ANS, Report ANSI/ANS-6.4.3, American Nuclear Society, La Grange Park, Illinois, 1991.

[16] S. R. Manohara, S. M. Hanagodimath, K. S. Thind and L. Gerward, Nucl. Instrum. Methods Phys. Res. Sect. B 266, 3906 (2008). 